\title{
From the Light of Children's Art
}

\author{
Ronald Silvers \\ Ontario Institute for Studies in Education
}

\section{Introduction}

I have chosen for this paper the study of children's art as a means by which I may pursue my interest in how the communicative expressions of a child are received and made meaningful by an adult's interpretive attention.

With this interest for my study, I describe an adult's (researcher's) discovery of meanings in his response to art works of the young. This description reveals the necessity and limits of a dialectical interpretive process for an adult's understanding of such art: There is a constant attention to separation and a concern with the tension of opposites. What is also disclosed in the interpretive process is an inherent objectifying of meaning as the researcher fails to recognize the child's spirit of consciousness, thereby creating a distance from her or his art and forming the child as "other" in relation to the self of the researcher. These divisive qualities run counter to the purposes of this study. Here, in a moving toward a reflective consideration of the problems created by a research intended to bring a greater bond of understanding between adult and child, I explore the significance of a unifying hermeneutics for human science.

The paper is composed of three parts. In the first, I present a background of my earlier research in the phenomenology of children's discourse in order to describe the basis of my interest in children's art and to offer a conceptual context for its interpretation within an area of hermeneutics. Part two is composed of my hermeneutic interpretations of five children's paintings and drawings. In the final section of the paper, part three, I present a phenomenological analysis of the process within the hermeneutic interpretation of the paintings and drawings, and, in reflection upon that process, attempt to identify its significance for the human sciences.

\section{The Context of Previous Research and Conceptualization}

In my previous studies of children's play and reasoning, I attempted to formulate how we, as adults, encounter ruptures of understanding within our conversations with the young-that is to say, how we experience a loss of socially shared meanings in our communicative relationship with children. These earlier studies explored the processes whereby we interpret children's discourse and how we impose externally based adult meanings upon their words and expressive 
gestures. I discovered through this research that the words used by children are often interpreted by the adult in terms of what is absent that the adult thinks is required in an understanding of discourse; in children's comments or questions adults are often struck by a contrast between what they would interpretively feel necessary to express in their own remarks, but find strangely absent in children's speech and writing. For example, children often initiate a description of their activities or their desires without an introduction of the context, topic, or theme of what they are considering.

Out of the silences of these ruptures I tried in my research to discover how we may reachieve a social bond between children and adults by surpassing the boundaries of an adult's interpretive universe through a phenomenologically reflective analysis and hermeneutic synthesis. Both areas of study are required. Whereas a phenomenological analysis uncovers and makes explicit distinctions and judgments within the process of an earlier preconscious understanding, a synthetic hermeneutics brings interpretation forward into a holistic union of understanding.

From such analysis and synthesis I learned about the restrictive character of language when language is taken as a limited study of a contrast between children's and adult's words, when discourse is understood from an adult interpretive judgment, when that interpretation is conceptualized solely within a concern with children's thought and reasoning, and when that thought and reasoning is assumed within a developmental conception of children's competencies. Alternatively I found that conversations between adults and children, as members of different interpretive domains, required a recognition of the boundaries of each domain, and especially a recognition of what is absent but necessary for adults to move beyond the limitations of their current consciousness for a more creative understanding of the young.

From the field work in classrooms and reviews of video-recorded Piagetian interviews, I learned that a surpassing of boundaries of interpretation in child-adult conversations required a receptive attention not only to what we regard as the realm of thought but also to the realm of sentiment.

To include the realm of sentiment in adult understandings of children's discourse is to open our awareness to changes experienced by our bodies and to bring those experiences into our own discourse. Including sentiment in discourse means including it in the language of research: Thus, we must move beyond field work practices of recording what action was visually observed and what utterances were auditorily present. In pursuit of the meaning of children's expression, research cannot offer an ethnography of the occasion, for an ethnography is neither adequate nor relevant in describing the researcher's experiences. Phenomenological descriptions must in- 
stead become a phenomenography, that is, an account of the researcher's experiences of thought as well as experiences of the tactile, the auditory, body movement and body heat in the search for the "appearance" of the object of study. Phenomenography is a recording of the biography of the subject's (researcher as subject) attention to an object of study as a reflective account of the way that attention was present within feeling and thought. For example, for me to describe how I learned from Loni, a four-year-old, the meaning of art and the practice of drawing, I must describe the vibrations I feel on the tips of my fingers as I repeatedly strike my pencil upon the paper, how I feel the drag of a wax crayon on its side as I move it across another drawing, how I shake the box of crayons and finger its broken pieces in selecting the next color, or how I wave my arms in quick rapid succession for a large scrawl. I cannot describe the play of children without reference to the warmth and smells of their bodies as we crawl over one another. The school piano is no longer an instrument of sound for arbitrary notes by an untrained child in a kindergarten class but, from my memory, the source of sound and vibration when I strike the three middle fingers of my hand upon its keys.

As these examples reveal, the inclusion of sentiment into a study of children's understandings enlarged my central research focus from a discourse of socially shared language (what we rely upon as the "conventional") to a horizon of gestures of expression (as those expressions claim our attention). I no longer concentrated my research on words spoken or written by children, but accepted various sources of expression based on sentiment. I now addressed expressions that appeared to stand outside of conventional language. With an awareness of this sentiment, I became attentive to the look upon children's faces, to the gaze of their eyes, to the gesture of their pointing, to the tapping of their fingers, and to the other movements of their hands. In general, I became sensitive to the shape their body would take in an activity and the meaning expressed by that shape. I took such gestural movements and shapes as not merely adjuncts to discourse but as principal sources of communication requiring my interpretations of their meaning.

The inclusion of the realm of sentiment in my research and the enlargement of my topical focus to include gesture as form required that I conceive communicated meanings outside of the intended purposes of the child. I could not propose what the child had in mind or wanted me to know. I began at this point to conceive of children and of myself and other adults as communicative participants with our separate and often dissimilar movements-of-attention, each receiving auditory, visual, and other forms that were new to our own world of understanding. Each of us was no longer enclosed in a different identity, unique history, and separate self. We were, instead, held within different interpretive domains which I conceptualized 
as separate cultures: adults' and children's. These interpretive cultures were themselves expressed within our movements-of-attention in time and space, movements which were, collectively and integratively, identifiable and meaningful in the shapes they assumed. In a rupture of silence, the adult is without a language that can be shared with a child, and subsequently without a way to restore a social bond with the child. At these times, the adult's interpretation centers upon the movements-of-attention of the childmovements-of-attention as dynamic expressions of form. These movements-of-attention are, potentially, sources of meaning. Attending to such shapes of attention allowed me, an adult with a culturally limited interpretive domain, to suspend what was ordinarily assumed or held typical for other adults or for children, and to follow a child's movement-of-attention. In this way, I was able to learn how play at a sand box included no project toward some desired end, how in the midst of play the constantly changing sand offered new potential of forms to be brought forward by the child, and how the child's efforts to realize such forms repeatedly created new possible constructions. I came to recognize how spilling sand became mountains, mountains became caves, caves became tunnels, and tunnels became bridges. The meaning of the child's activity was what he or she expressed as the changing landscape of the sand.

To be present to the changing landscape of the sand, I had to again reconsider, "What are the sources of experience?" To the qualities of thought and sentiment (sources of mind and body), I now included imagination. What is allowed in imagination (that is, what we allow for ourselves) is the creating of images as a flow of attention, a flow that retrospectively follows a movement-of-attention. This imagination is not a projection, a fantasy, as we often conceive in terms of different realities (Schutz, 1971, pp. 207-259). The imagination that I speak of is a recognition of what is offered by an unknown source within ourselves, a source which spontaneously and effortlessly grasps a totality from former particulars; imagination is a leap forward in understanding; in this way, imagination is experienced as an "insight" allowed by suddenly lifting conceptual limits; in the immediate, spontaneous presence of imagination, we sense that we are given a gift of understanding.

Having discovered within my field work experiences the possible limitations and potential problems of interpreting discourse and the significance of sentiment and imagination in an understanding of the young, I began to reflect on the composition of research discourse-namely, how we may speak and write in a manner which expresses the full spectrum of what we have discovered and interpreted in our understanding of children, and how these new understandings may become a part of adult consciousness. My formulations of the communicative understanding of children were 
about the process of interpretation: how such a process became limited by the structure of human science inquiry and how to move beyond such limitations. I regarded the discovered meanings of a child's work or play activity, or an enlarged meaning of a word a child used, as of lesser importance than that of discovering the significance of my interpretive process as an adult. Substantive knowledge gained about children's talk, play, and work was of secondary value to the purpose of discovering how an adult-researcher came to understand the meaning of children's action and discourse, and eventually came to a reinterpretation of their gestures. The main effort was to uncover, recover, and conceptualize how a researcher may surpass an adult cultural meaning and how that researcher may arrive at new meanings within and for children's activities which would ultimately bring a closer existential bond between adult and child. The attempt then was not for an epistemic knowledge of the features of children's or adults' understandings, but a dialectical (that is, transfigurational) knowledge of interpretive meaning which broke through the bonds of separate cultures.

The focus upon process of interpretive understanding revealed that a shift from silence to communicative meaning was a transfiguration of adult knowing. I concluded from my previous research that the process of transfiguration from one form of understanding to another, and in reflective conceptualization from one consciousness to another, was the primary contribution of an effort to achieve a communicative bond with children. It was communicative insofar as the "walls of culture" between adult and child were suspended such as to allow a person to receive openly and without predetermined meaning the expressions of the other. Communication did not assume interacting (direct or indirect) participants, but an offering and receiving of expressions for interpretive reflection. Descriptions of this process for other researchers and for well-informed citizens (the nonspecialist in Schutz's terminology) (Schutz, 1964, pp. 120-134) offer a potential of transfiguration for those who receive such research as a text for their reflection. This type of knowledge is dialectical and intertextual, ever changing and yet linked by the entrainment of texts as they move forward with future interpretations.

Hermeneutics in the human sciences currently moves in two directions: one, in pursuit of Marxist critical theory, such as is found in the works of Jurgen Habermas; and the other, central for this paper, in pursuit of securing the ontological significance of human understanding, as outlined in the writings of Hans-Georg Gadamer and present in the studies of James Agee, Roland Barthes, and Carlos Castaneda. Ontological hermeneutics makes us aware of the foundational sources of our existence. Within ontological hermeneutics a series of questions are posed about what transpires in daily life that is neither consciously chosen nor culturally determined, 
questions which bring us to confront and recognize human limits and to seek human possibilities. Therefore, hermeneutics in the human sciences in the way it is conceptualized within this paper offers neither a method of research nor a theoretical system for interpretation of discourse or other forms of expression. Rather, hermeneutics is a field of study composed of descriptions of processes of interpretation, descriptions which make us aware of, and sensitive and responsive to, the communicative understandings of others.

Formulated from my field work, from my concern with the nature of research discourse, and from my reading of hermeneutical studies in the human sciences, I have become aware of three principal features of the interpretive process that appear in my inquiry:

1. An ontological hermeneutic begins with an existential stirring within the researcher's biography, a stirring amplified by meaning as it is shared with others in discourse.

2. An existential responsibility for authorship of a research text is secured through a reflective discourse, that is, a discourse which constantly turns upon itself to discover the tacit understandings of what is its spoken and written words.

3. Interpretive knowledge is dialectical, offering descriptions of transfigurations in the researcher's understanding of self and the subject of appearance.

\section{Discovering the Paintings}

The paintings and drawings selected for this study were chosen from submissions to the Shankar International Children's Art Competition held each year in Delhi, India. Over 150,000 paintings from more than 100 countries are submitted annually. I spent a week in 1983 and the same amount of time in 1984 examining several hundred paintings of a preceding year's collection. From my review in the two years, I selected a total of approximately 50 works.

My selection was not based on any predetermined categories or criteria. I chose paintings that I found expressive and that claimed my attention in an immediate and preconscious manner. I selected a work when at first sight I recognized something important, but could not name what I had found or explain the reason for my choice. The purpose of this process was to assemble a set of paintings which would evoke interpretation, but not a conventional adult understanding. Similar to Barthes' study of photography, I wanted to include for study those visual works that "I was sure existed for me ... I decided to take myself as mediator for all . . . [images]" (Barthes, 1981, p. 8). It is through this selective process that I would be able to begin with the existential significance of a child's work of art-what Barthes would term the punctum-rather than dwell upon the cultural domain-what he calls the studium. 
The three paintings and the two pastel drawings discussed in this paper were selected from the total collection I brought to Canada. After the initial painting, "A Poem," was interpreted, the four other works were chosen by the same process of preconscious significance which I have just described. I discovered that each painting or drawing that I interpreted led to a question or unresolved issue of meaning. With such a problem in mind, I would search among the remaining art works in my collection in order to discover/construct another hermeneutic synthetic interpretation. There is through this practice a progression of "recognized" meaning, a serial movement in discovering the next necessary text within a moving problematic (Darroch and Silvers, 1982, pp. 177-179), a moving problematic that would bring me to a meaning of children's art.

\section{A Poem}

Noah's ${ }^{1}$ painting" is called "A Poem," but I do not find it as such. It is for me a dream, a casting of images which float: These images are present beyond my wide-awake world of what I see. If I look at the painting, if I try to see it, apprehend it within my vision, the painting escapes me. If I try to discover what is there that takes hold of my feeling, then my willfulness goes around it, stays outside of it. I must relax my gaze to receive the painting. I must suspend my desire in order to become a part of it.

This struggle to accept Noah's painting and to accept her naming of it is an effort to cease wanting to locate the meaning of this visual work and to find the meaning of my sentiment which has moved forward and which has become a part of its text. I must give up my search for understanding in order to discover the meaning of "A Poem."

To do so means that I first must leave the text of the painting for my text of previous attention. This leaving of the text, I discover, is at the moments of turning from or to the painting. It is when the painting is not in its corporal presence before me, but is proximate to my own presence. The presence of the painting allowing the interpretation of its meaning is only there in the tensive moments in which the image is in reflection rather than "in sight."

I have written that Noah's painting is a dream. Such a naming, however, is not sufficient. I have not said enough, though that is all that I have said. I return to the painting, but now, rather than looking, I am aware of the moons: They are luminous. Their brightness fills the picture, fills me in their presence, fills the magician who flies through the air. The magician calls the moons on his horn, that silent instrument. It calls the two moons in the sky and the one below. The horn also calls me from beyond the frame of the painting. 


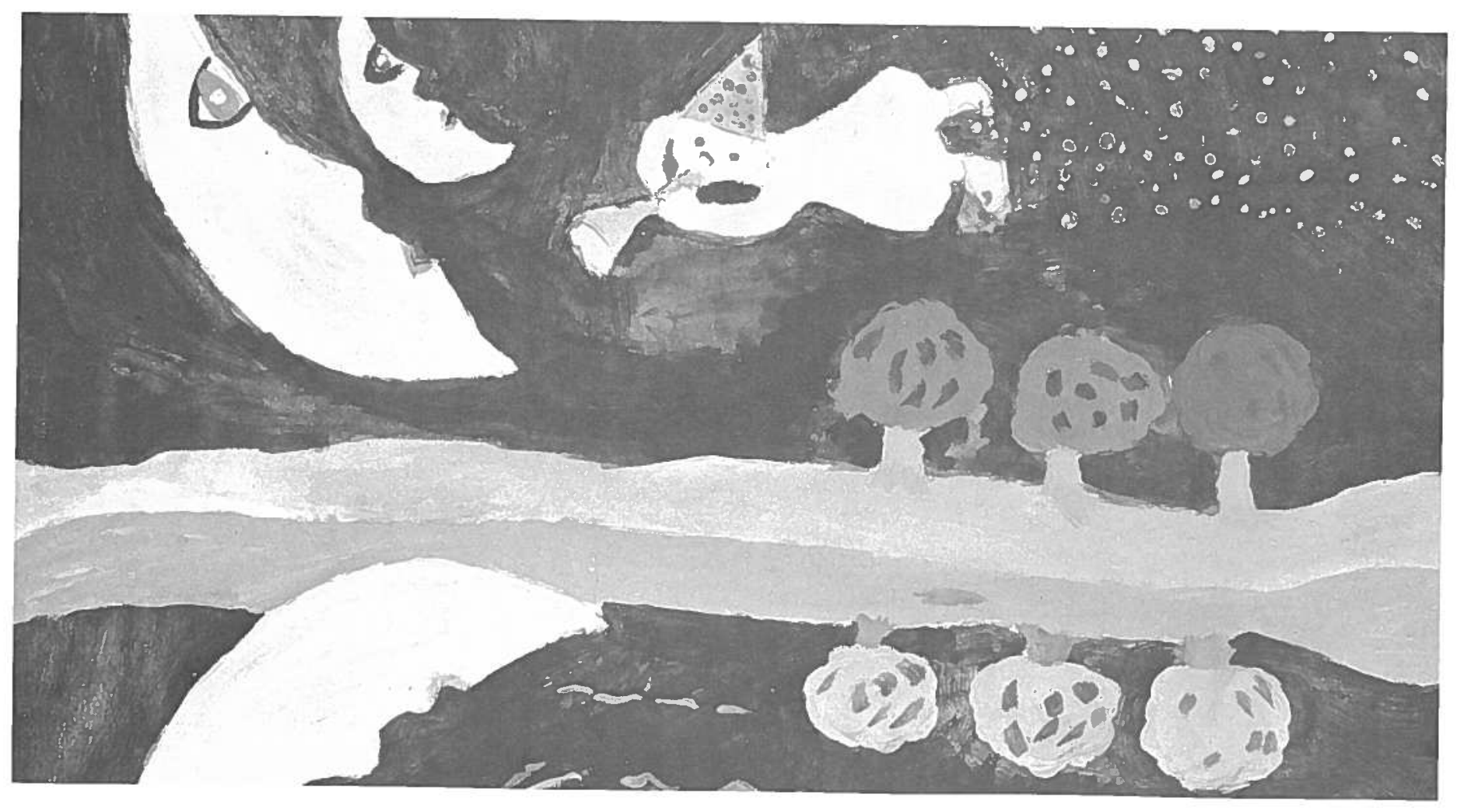

Figure 1 
The moon of the water looks downwards. The moons of the sky, upwards. The downward moon mirrors the sky moon, but it is not a reflection of it: that moon of the water. It has broken away from itself, from its place in the sky. That moon below, that moon is falling, it is going toward the water, into the water from the sky. And when it sinks it will leave ripples in the water, as the ones that are now there.

And the trail of the stars; they are upon the water, not reflected in the water. That trail of stars sits upon the water, split away from those of the sky.

The bank of land; it is in two, dutiful with two sets of trees. The bank of trees, they have also split from themselves, an opening of one into two.

This splitting, these halves, I have not seen their movement, but I know that they have just occurred only moments before. The painting shows me not what is here now, but what was just there only seconds ago.

The call of the magician; he is the only figure which yet moves, the only magic which is now as it was before the split. He is here with his trail of stars, but he is not upon the water.

This halving, it makes way for the magician; this halving is an opening for his flight. In his travelling he calls upon his horn, "A Poem, A Poem." He repeats in his movement across the sky, "A Poem."

"A Poem" then is not the meaning of the painting. "A Poem" is not a frame for understanding the content of Noah's expression. "A Poem" is the magician's call, a sound which splits the world in two.

The halves are not uniform, not entirely balanced and symmetrical; one does not complete the other. The halves are only complementary in their original wholeness which they no longer secure. The smaller moon of the sky is not below, falling toward the water. That smaller moon has not split. And the tree on the right, its darkened branches cannot find themselves below in the other tree. So too the two trees to the left, they do not hold the luminosity of their halves resting upon the water.

These halves shall never be the same, nor will they provide for the wholeness again. Is that the call of "A Poem"?

All that I have just written resides between the experience of the painting as a dream and the appearance of the painting as it is visually present to me. The latter is a text, whereas the former is an awareness. For in my awareness of the painting I find not what is corporally there, not what is even symbolically there in the cultural or historical sense, but a reference to what is within my attention, an 
attention bounded by the sentiment of my body and by an acceptance of a lyrical meaning on my way to and from the text.

The magician in flight, he is represented in movement by the trail of stars. But my own movement, that is to be found in reading into his movement and into the call of his horn, "A Poem." This call, which signals my immediate separation from this child's expression, is from an understanding which is broken away from her expressed meaning. But my understanding of "A Poem" as a dream existed in wholeness with Noah only moments before the call. Reflected in my interpretation is a broken unity of "A Poem," which I find in my own words, as these words are a part of a process of what is given to me in the appearance of the painting. There is within this process an act of dividing, an act which is the call of the meaning (that horn which signals), a unity lost but not forgotten. It is this unity which the interpretation seeks. It is this recomposing toward synthesis which my words seek.

\section{A Cow}

A voluminous face of "A Cow" (it is so titled) staring out at me. It. has turned to look in my direction, with an open mouth of round red lips, soft eyes, and textured body. It is almost still upon the paper. There is within this cow a composure of a person. The eyes are inviting, its mouth about to speak (or is it speaking now?).

Upon the face of "A Cow" I find a look which is neither of a dairy animal nor of a human. There is another kind of sentient being in this painting. As I gaze at its form I lose the distinction, the separation, between human and nonhuman beings. This loss is not by a blending of human and nonhuman, but in how this being is otherwise. There is here no distinction, no separation, between this being of feelings and emotions and the feelings and emotions ascribed to men and women.

Somewhere there is a tension in the drawing. But $I$ find that it is undiscoverable: Each aspect of "A Cow," its size, texture, and facial features are both strong and soft. The look of the eyes, the red round mouth, and most of all the textured coat contain dualities. The cow is pictured large, and yet it appears to float.

Here is my problem of understanding: There is in this drawing no dialectic in its inherent differences, that is, this cow, as a sentient being, encompasses both strength and fragility, weight and airiness, and especially the softness and yet roughness of the textured coat. There is in its being a copresence of qualities which I normally take to be at odds with each other, but here these features dwell together with an ease of composure. I look unsuccessfully for disharmonies, for the tension of difference. But what I interpretively anticipate fails to appear. 


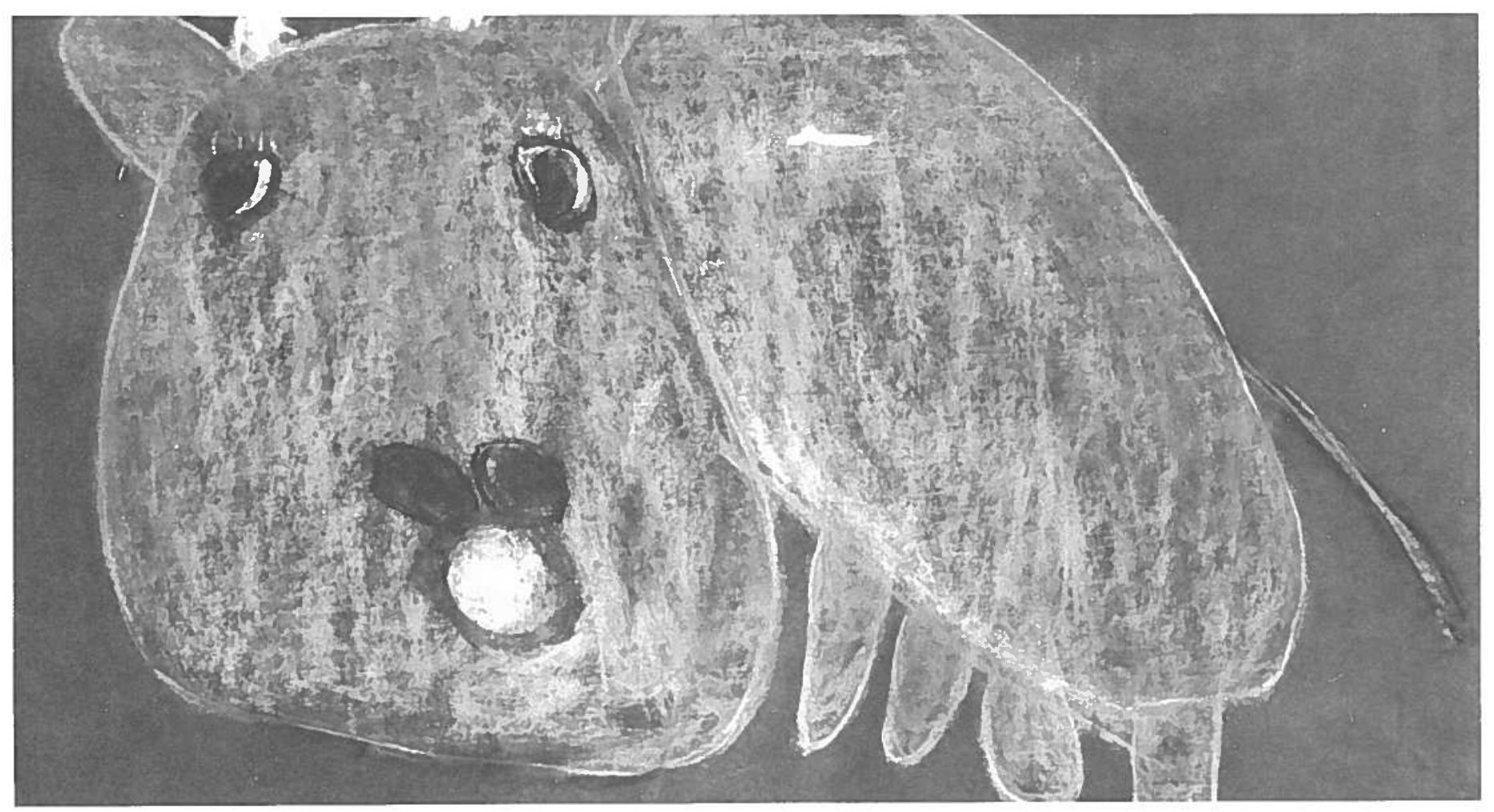


The dialectic that I seek to find is not within the drawing of "A Cow," but elicited by its appearance from me, the viewer. The dialectic of my own text is a looking for, but a failing to receive, that which the drawing offers me, the adult. This gentle sentient being is but my other, my anticipated otherness of disharmonies which I seek within a child's painting. But to accept the otherness of "A Cow" I must first lose my judgment for distinctions. I must accept a world undivided by differences.

\section{My Mother}

A largeness of person, a largeness of form, a face that feels close to my own (it almost touches my cheeks) as I look at this pastel drawing at arm's length.

This figure does not register humor and yet this figure brings a smile to my lips. The work is rendered in a serious manner, but with lightness, a floating figure made possible by a bulbous head atop a smaller rectangular body. Then I realize that my smile is a registering of joy: Here is a figure whose size may both fill space with its strength of presence and yet attain an airborne (aerial) movement.

I turn the pastel drawing over to find that four-year-old Tammy has titled her work "My Mother." As I begin to turn back to the figure, it is no longer the head which claims me, and I realize that the effort of the painting is in the limbs/hands that extend at the body's centre; they emerge from the side of a blue coat.

The limbs at the side of the body appear as flowers growing from a blue torso, growing horizontally, each with a short trunk and many branches. The arms are formed but not full. They appear in a potential, but not in actual size.

The arms/hands are proportional to the rest of the figure not by size but by the absence of color. Whiteness among these pastels carries them to the greatest prominence even moreso than the blackness of the hair.

The whiteness, the anima (Jung, von Franz, Henderson, Jacobi, \& Jaffe, 1968, pp. 186-197), the female shadow, the feminine, the receiving, the caring.

Here, as with the painting "A Poem," I find the title of a child's art not within its content, but within the form's gesture (that which is given by form). "My Mother" is called out in the horizontal white limbs about to grow and in the elongated fingers which are about to caress.

But the maternal is not offered in the present by Tammy, nor even in the past (as the moment before appearance in Noah's "A Poem"). My mother is offered in a temporal horizon of to be present, that is, 


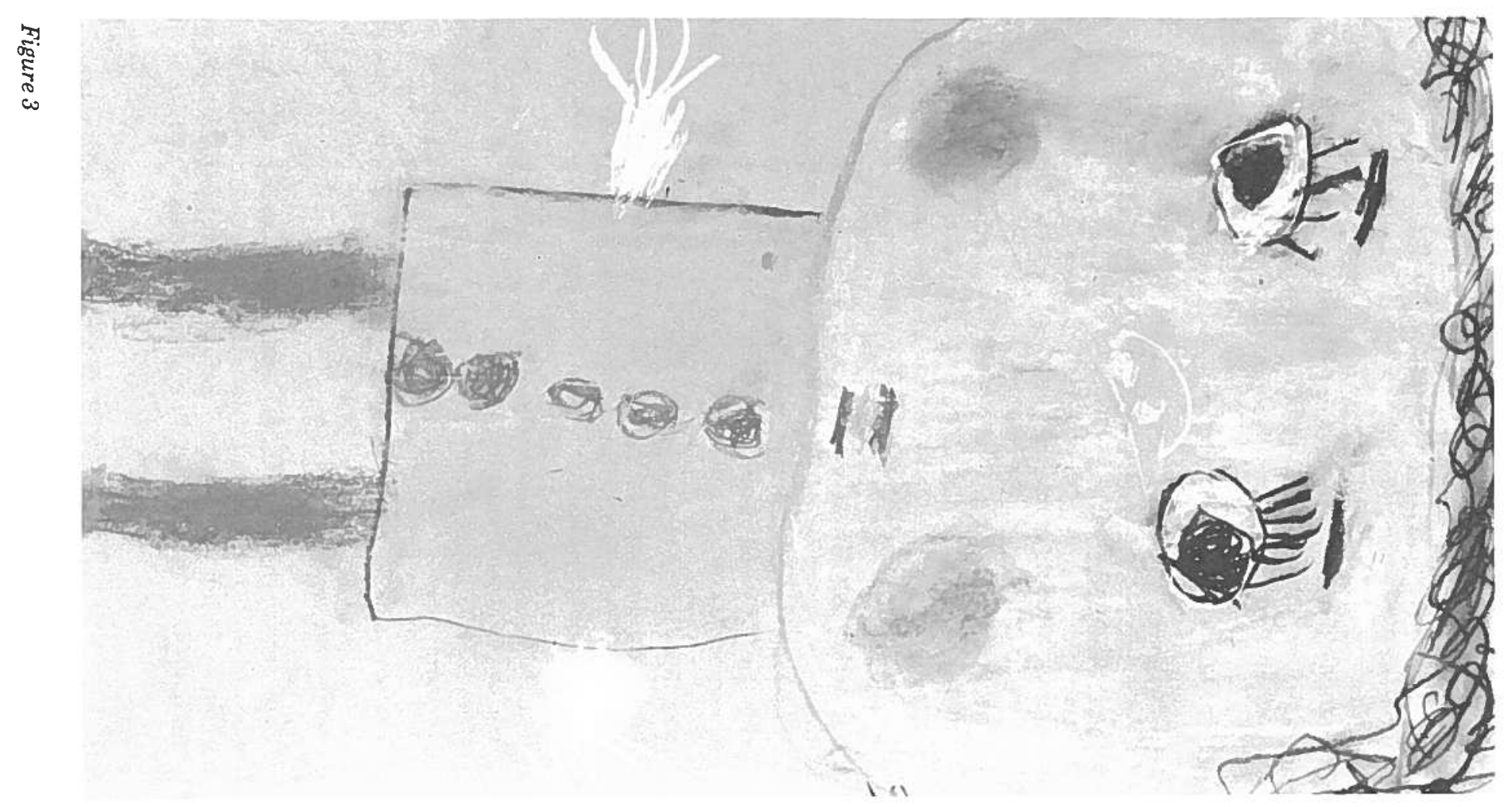


in what is to come. I recognize that against the solidness of the rest of the body, the short white limbs are the potential of "My Mother."

And this openness to receive, this maternal gesture, is offered to me the viewer. Communicated in this pastel is a gesture of waiting, an invitation to receive, an offering to accept without reserve and without exception. My own process of understanding is here a quest of unprescribed meaning. No tension of dialectic precedes my understanding of this drawing. (Have I learned from the meaning of the pastel drawing "A Cow"?) My potential to find understanding may be written upon an absence of color in these white arms/hands. There is here no separation of intended meaning between a painting's text and my own text of understanding. There is no text which imposes and requires its own bounded historical significance. Whiteness is, for interpretive purposes, a beginning of imagination, a state within which feeling and thought may be scribed/spoken upon a child's painting without intruding upon that painting, without the painting intruding upon the viewer's discourse.

\section{My Mother and Sister}

Too strong, too intense for a child's painting? My immediate mental flight is to the psychological: I engage in an evasive interpretive practice by moving from receiving an expression of a child to receiving a communication from a disturbed mental state of person.

I wonder about the artist's ability to discern reality/unreality, about his or her family context; I begin to imagine a life expressed through a veil of a psyche which distorts or exaggerates and creates a bizarre figure upon the paper.

The eyes, they say too much for the artist to be a child: Those eyes do not speak of a fresh imagination, of a series of new horizons and discoveries, of an unburdened world of the young; those eyes express scars of emotional pain.

There is in the eyes a deadening, a blackness, a loss in which I cannot find the child (either in the one pictured or in the artist I try to imagine). I must look away, turn from the figure on the paper and thus be released from my own service in order to discover a new meaning of the text of the painting.

I search for the artist. A label attached to the other side of the paper informs me that this work is by a four-year-old Korean girl and she has titled the painting "My Mother and Sister."

This sister with a golden face and dark circles around her eyes; this sister's eyes are well formed. At first glance these circles do not appear as a part of human organs of sight. But then as I dwell within these spheres, as the dark rims appear less pronounced, these eyes gain a softness, a gentleness, unexpressed elsewhere in the face. 


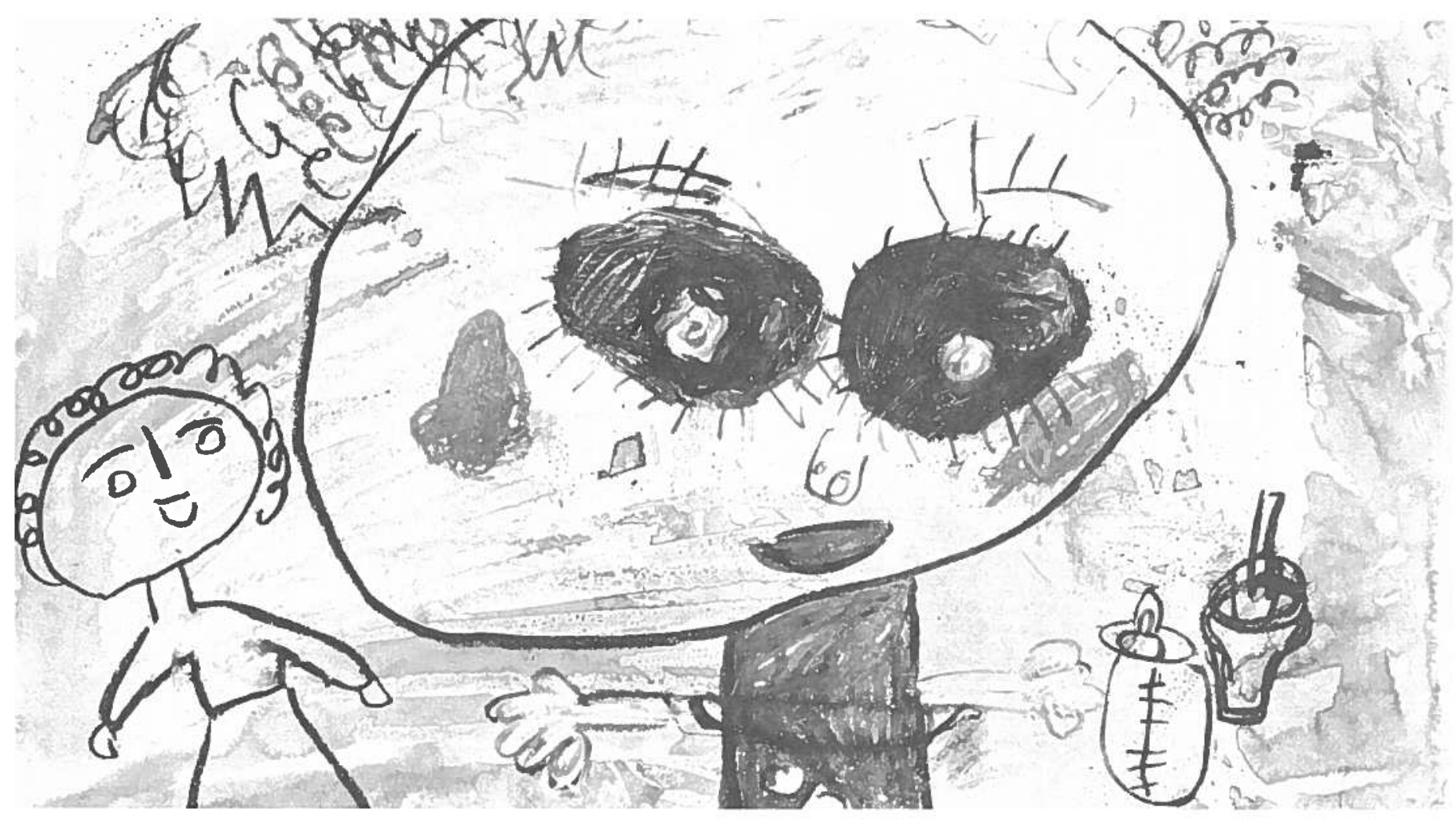


There are strokes of blue that earlier I had not noticed. There are brown pupils and a gesture of a look suggestive of sight.

These eyes appear still when the rest of the head, especially the hair, is in movement.

It is as if the look upon the face is one of upheaval while from the caverns of the dark circles, another look is emitted, a gentle, sustained stare.

Is this look upon the eyes registering the discovery of an Other? The painting expresses to me a composite enclosing a stillness of the sister's eyes (a look outward), encased within a body of unquietness. These eyes are the eyes of a sister looking at the painter. These eyes are a sister's eyes looking at me, the viewer of the painting. It is only in the still-point of the eyes that I find a union of the sister, the artist-child, and myself the adult-viewer. Within these eyes is an Otherness of all of us, a union of common humanity.

\section{Horses}

Where to look, where to let my attention settle? There are horses in profile, horses white with black, white, or grayish manes and tails. There are horses looking left, horses turning to see what is behind them, horses with their tails down and with their tails raised. And there is one horse with its head toward the ground, as if to smell and perhaps eat some blades of grass. Some of the horses are mounted by people (children?) and one is held by a larger person.

The eyes of these horses are darkened, some fully blackened (are their eyes closed?); for some horses the pupil appears forward toward their nose, and for others, the pupil is placed back toward their ears.

And the feet of the horses, sometimes white, sometimes golden, and always with black hoofs.

As I stare at the painting my eyes dilate. I cannot hold to one horse: they mix before me but they never blend together. The horses crowd my vision with their plentitude.

And then I come to see these horses as one, the many of them become one; in this painting, simultaneously, is both a plurality and a singularity.

There is here The Horse as many horses and the many horses as one horse. I speak not of an abstract essence from a material world, but a world which appears as a unity of multiplicity. This is not a realization in thought, but an insight of the imagination: suddenly, excitingly given, a realization that what is in a plurality is still but one. 


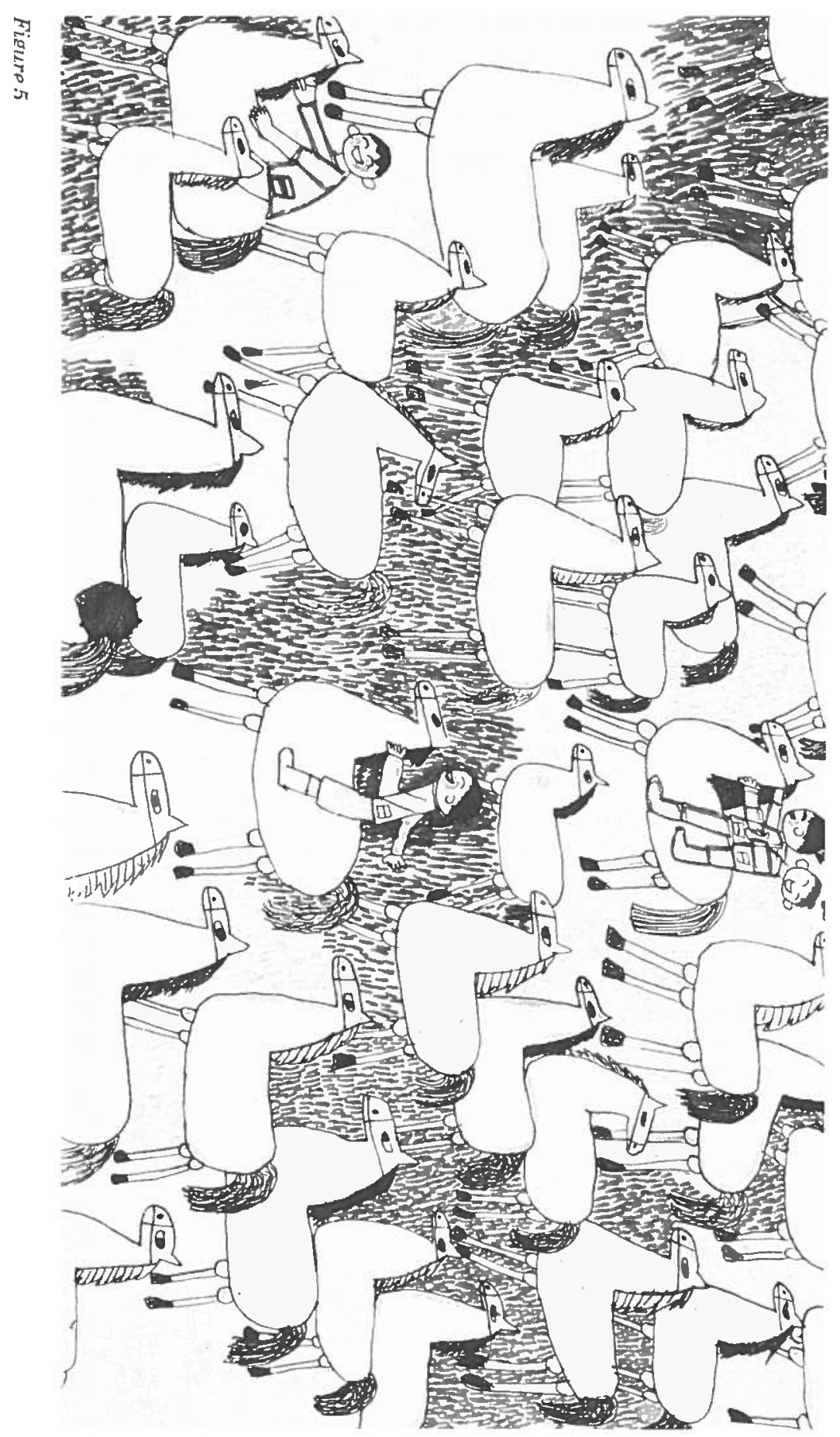


I am forced by this painting of horses to look at other children's paintings simultaneously in their detail and in their totality. Part and whole are not different values. Each is constituted in the functional other and each requires my attention without separation. For here in children's art, meaning is not constituted in the one, nor in the many, for only in the many is the one, and only in the one are many. Only in retaining within ourselves, within our own being, the figure of each sentient being is a unity of our world permitted. Only in an attention to each painting, an attention undivided by the many paintings and undivided by an expectation of significance to a social category which accords an identity called "child," is a unity of art permitted.

\section{From the Light of the Art of the Young}

There is within the interpretation of these five paintings and drawings a movement-of-interpretation. In this movement-of-interpretation, similar to the movement-of-attention in understanding each painting and drawing, there is a process which, as a direction, creates a shape or form. It is this static rendering of the process into a form which interpretively offers a signification of meaning. Therefore, by uncovering that movement-of-interpretation for each of the works of art, and by continuing to search for the line of movement from one to the next painting or drawing, the process of understanding may take place. I will now take the hermeneutic "design" within the previous section and examine it phenomenologically in order to discover, and conceptually to recover, the meaning of an interpretive process. What I attempt in this phenomenological analysis is to explicate the practices of hermeneutic reflection and to discover the sources of these practices in an effort to reveal an ontic foundation in this study of children's art. By the ontic foundation, I refer to the essential and existential qualities of our Being in the world.

"A Poem" begins the journey of understanding children's art. It is a painting showing division, and yet the very images of that division point away from separation to an earlier time of unity; while the division casts the viewer forward in tension of parts separated from others of their likeness, implied is an earlier time of wholeness. There is, then, a unity lost and a unity to be found, a tension of one state to the other, which conceptually may be thought of as a dialectic.

The concept dialectic denotes such division and tension, and yet dialectic also refers to a thoughtful discussion involving opposed assumptions; a dialectic is a conversing-a dialogue-in which there is a thinking in opposites - opposed assumptions (Gadamer, 1980).

Here, as a hermeneutic dialectic, communication of children's art is for the adult an interpretation and liberation of expression that 
signifies a composite of opposites. Yet, these opposites offer different movements. The division is not static. The dialectic of children's art points forward and backward to an absence of division, to a complete, whole world that is not immediately present. The backward movement in "A Poem" announces a unity lost and from that loss casts the viewer/interpreter forward in search of a world undivided.

In "A Cow" there is a first glimpse of opposites that are not in tension: the soft and the hard, largeness and lightness, and so forth. Here the dialectic lapses in its own conditions; dialectic suffers from its own contradiction and becomes, instead, a negative dialectic. Thus, the "giveness" of dialectic is not firm, but gives way to a mutual harmony of qualities that normally are in tension. It is this negative dialectic which forces meaning beyond its own limits: a realization that what is normally in tension may be in harmony; the logos of the world is broken immanently from within itself (Sorokin, 1962, Chapter 12), carrying with it an opening of interpretive limits. While unity is not regained in an interpretation of "A Cow," division is no longer maintained. This is a nether world of understanding no longer secured in a foundation of reason (first the loss of unity and now the loss of the dialectic itself), and yet, this is a potential world of transfiguration.

Where may unity be regained? The first place is in the figure of "My Mother," a figure of receiving, caring, caressing gestures which are offered without reservation. This figure in the drawing is suggestive not in the present, but in the potential of the future, a potential not for one but for all humanity. "My Mother" is a signifier of arms and hands, a sentiment that offers a mingling of bodies, a mingling of unconfined worlds. Before a new reason is secured, a sentiment offers a movement-of-interpretation. We may hold a completeness of the world within our bodies before we hold it in our minds; therefore, we must seek what sentiment offers the intellect.

In "My Mother and Sister" this potential is again expressed, but this time the possibility of a unity of Being is found in the communion of "a look." There is a bond offered in the eyes of a disturbed child within the painting, a bond between that figure, the artist who painted it, and the viewer. The look cast by the figure in the painting is the only one available to both artist and viewer. The work of art not only enlists the viewer but shows the viewer's place in an acceptance and caring amidst a frenetic world. Now it is the viewer who becomes the feminine, as "My Mother," to care, to receive, and to caress.

"Horses" appears to complete a circle: The division of the dialectic multiplies into a plentitude of images but out of this very plentitude there is a return to unity. Thus, for the five paintings, an adult's interpretation of children's art is a "circle of understanding," commencing in a division that breaks the world in two, a break which 
first gives birth to a dialectic, a dialectic which ultimately undermines itself, and from that loss an opening which returns the world as a totality. The process of this circle of understanding, I believe, necessarily includes the dialectic, for the attempt to find meaning begins with a question that prompts inquiry (the need to know and the quest for knowledge creates objects of study through a process of objectification that separates the inquirer from the very world in which he dwells). It is here that a world whole is shattered into object and subject, and yet a hermeneutic venture allows an uncovering of the process of objectivation (objectivation as the manifestation of our consciousness in every action), and in what lies behind this process the totalization is reexperienced. This very venture offers a consciousness of the path from a loss of unity to full communion.

Indeed, the art of the young calls upon us to look at a unity of the world, to recognize that the world's inherent destructiveness is in our distinctive presence (in an analytic gesture of inquiry), and to recognize the potential of that unity again in our creative gesture of constituting meaning.

In a hermeneutic interpretation, what is present in the text is made available (contextualized) by the viewer's/hearer's/reader's practices of interpretation. In a hermeneutic interpretation circumscribed by inquiry, the practices of science constitute a contextualizing feature. Collecting materials for study, reflecting upon and conceptualizing the process of interpretation, and especially rendering meaning within a problematic (here an attempt to discover the process behind the construction of meaning for children's art), creates a reality of what "appears." But inquiry, as I have discussed elsewhere (Darroch and Silvers, 1982, pp. 173-214), creates a distance between researcher and the subject of research: adult and child. Hence, in this study an object of children's art is treated at a distance from an adult interpreter. Age categories become signifiers of an alienation, requiring the adult-researcher to shift realities in order to surpass this estrangement. This shift is found in the discussion of the painting "A Poem," and again in the description and judgment of the painting "My Mother and Sister." The focusing within the treatment of each of these paintings changes from a conventional mode of understanding (from what is expected to be shared by others) to a "dreamed" (imagined) construction. We can see in retrospect that this change of focus mirrors the process of alienation inherent within scientific inquiry. A hermeneutics circumscribed by such inquiry suffers from this alienation, but as a field within the humanities, hermeneutics signifies a process of transfiguration moving out from and beyond this alienation. Each study interpretively is a reflection, a parallel of significance, of the structure of its inquiry. The structure of inquiry mirrors the problem of investigation, creating within its practices 
and its ideas what is thought to be separate from the researcher. Yet, ultimately, the researcher comes to find the meanings of the phenomena are also the meanings of his (often alienated) relationship to those he studies.

Hermeneutics must be released from science to pursue the human. Hermeneutics shows our existential quest from alienation, our attempt to become fully present in our humanness (intellectually, physically, and spiritually). Therefore, hermeneutics is a process of creating meaning, a way of forming symbols which inform us of our existential circumstances and the ontic possibilities. Human science as a combination of phenomenology and hermeneutics offers a dialectical possibility for this release. Human science is both system (a centripetal force) and imagination (a centrifugal force). An analytic phenomenology pulls inward toward conceptualization and epistemology. A synthetic hermeneutics pulls outward to a horizon of new meaning, new consciousness, and the possibilities of a new social order. A hermeneutics for (but not of) the sciences reveals the nature of intellect, sentiment, and soul as a unified and unifying state of Being, permitting the scientist to regain a center within the world and allowing for a new world.

Within the adult's domain of interpretation, the burden of language and the constraints of the moral order are conceived to have not yet fallen upon the young. The young are complete, hence not competent in a dualism of a material world. For the young, the world moves from and to union in a flux of the whole and its division, a movement that does not succumb to the constraints of an unyielding dialectic. The hermeneutic interpretation within this paper is a returning to a consciousness of synthesis. The five paintings and drawings illuminate the way for this consciousness. A division and inequality within age categories of child and adult is necessary at the outset of the study. Within the art of the young (the young of any socially defined age category) we discover a knowledge lost in modern life, a knowledge we seek to regain. In the birthing of new meaning, a reflective hermeneutics is a seeking of the young within the human sciences and within ourselves as researcher.

\section{Notes}

1. Names of children within this paper are pseudonyms in order to protect their identity.

2. Because of publication restrictions, color paintings and pastel drawings referred to in this paper are reproduced in black and white. 


\section{References}

Barthes, R. (1981). Camera Lucida. New York: Hill and Wang.

Darroch, V., \& Silvers, R. (Eds.). (1982). Interpretive human studies. Washington, DC: University Press of America.

Gadamer, H. (1975). Truth and method. New York: Seabury Press.

Gadamer, H. (1976). Philosophical hermeneutics. Berkeley: University of California Press.

Gadamer, H. (1980). Dialogue and dialectic: Eight hermeneutical studies on Plato. New Haven: Yale University Press.

Habermas, J. (1971). Knowledge and human interests. Boston: Beacon Press.

Habermas, J. (1973). Theory and practice. Boston: Beacon Press.

Jung, C., von Franz, M.L., Henderson, J.L., Jacobi, J., \& Jaffe, A. (1968). Man and his symbols. New York: Dell.

Schutz, A. (1964). The collected papers $I I$, studies in social theory. The Hague: Martinus Nijhoff.

Schutz, A. (1971). Collected papers I, the problem of social reality. The Hague: Martinus Nijhoff.

Silvers, R. (1977). Appearances: A videographic study of children's culture. School experience. P. Woods \& M. Hammersley (Eds.). London: Croom Helm.

Silvers, R. (1983). Un the other side of silence. Human Studies. 6(1), 91-108.

Sorokin, P. (1962). Social and cultural dynamics, Volume Four. New York: Bedminster Press. 